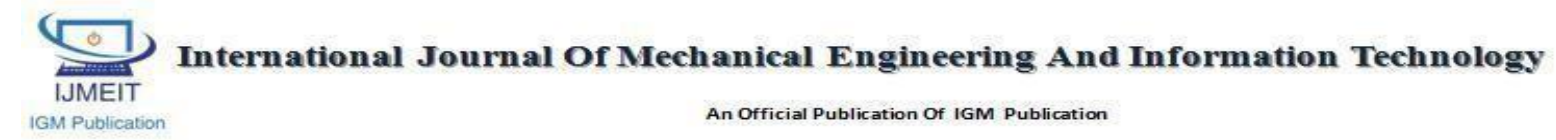

Impact Factor: 3.154

DOI: http://dx.doi.org/10.18535/ijmeit/v3i7.01

\title{
Stress Analysis of Bolt Used to Connect Two Plate in Circular Array Pattern And Rectangular Array Pattern For Load
}

Authors

\author{
Sushil Patil1 ${ }^{1}$, K K Chaudhari \\ ${ }^{1}$ P G Student Department of Mechanical Engineering J.T.Mahajan collage of Engineering, Faizpur \\ ${ }^{2}$ Associate Professor Department of Mechanical Engineering J.T.Mahajan collage of Engineering, Faizpur \\ Email- patilsushil204@gmail.com
}

\begin{abstract}
Many methods exist for bringing together similar or dissimilar structural materials, in terms of the joining technique utilized. Conventional mechanical joints, such as bolted, pinned or riveted are preferred due to their simplicity and the dis-assembly ability that they offer for joining metal or composite materials. However, when a mechanical joint is loaded, local damage is induced at the fastener holes due to stress concentrations. This fact leads to the structural degradation of a joint and jeopardizes the structural integrity of the assembly structure.
\end{abstract}

Key words- Array pattern, Mechanical Joints.

\section{Introduction}

Many methods exist for bringing together similar or dissimilar structural materials, in terms of the joining technique utilized. Conventional mechanical joints, such as bolted, pinned or riveted are preferred due to their simplicity and the dis-assembly ability that they offer for joining metal or composite materials. However, when a mechanical joint is loaded, local damage is induced at the fastener holes due to stress concentrations. This fact leads to the structural degradation of a joint and jeopardizes the structural integrity of the assembly structure.

Threaded bolts are widely used in engineering to hold two or more parts together. The failure of the threaded bolts can lead to the catastrophic failure of the structures. Determination of ultimate bearing load and prediction of damage evolution for threaded bolt are critical to evaluate the integrity and safety of most engineering systems. The design of bolted joints is heavily based on experiments now a day's most studies have been focused on the ultimate bearing strength of the bolted joints. Investigated the bearing strength and failure process for double lap bolted joints under a static tensile load. Showed that the bearing strength of the bolted joint is largely depending on the clamping force. Improved numerical analysis methods are needed to reduce the expensive and time-consuming experiments.

\section{Objective and scope}

\subsection{Problem formulation}

The inclusion of bolted joints in aircraft structures leads to regions of stress concentration. Composite materials are relatively brittle and typically offer limited stress relief through localized yielding compared to metals. This, combined with inadequate failure prediction capabilities, can lead to conservatively designed composite bolted joints which amount to severe structural weight penalties. Bonded joints offer higher 
structural efficiency, but limit accessibility and can increase manufacturing and maintenance costs. Optimizing composite bolted joints using improved modeling tools thus continues to be a priority for air frame manufacturers. Countersunk fasteners are of particular interest for use in skin-structure joints where aerodynamic efficiency is important. Many of these joints are single-lap in nature. Single-lap joints result in significant stress concentrations and lower bearing strengths compared to double-lap joints, while countersunk joints clearly involve a highly complex stress distribution in the laminates. Thus countersunk, single-lap joints are of critical importance to the aircraft industry, but are also the most complex type to analyze. To date, there have been few detailed studies on this type of joint.

\section{Mathematical Modeling}

\subsection{Sample Calculations for maximum shear stress For M8 and M10}

(Where Load $(\mathrm{P})=2000 \mathrm{~N}, \mathrm{~A}=$ Area for shear and tension, $\mathrm{n}=$ Number of bolt)

$\mathrm{A}($ for $\mathrm{M} 8)=\pi / 4 \mathrm{x}(\mathrm{d})^{2}=\pi / 4 \mathrm{x}(8)^{2} * \mathrm{n}=2000 /\left(\pi / 4 \mathrm{x}(8)^{2} * 8\right)=4.973 \mathrm{~N} / \mathrm{mm}^{2}$

$\mathrm{A}($ for $\mathrm{M} 10)=2000 /\left(\pi / 4 \mathrm{x}(10)^{2} * 8\right)=3.183 \mathrm{~N} / \mathrm{mm}^{2}$

$\sigma 1, \sigma 2=(+-) \sqrt{ }^{2}+\tau x y^{2}=0$

$\tau \max =(\sigma 1-\sigma 2) / 2$

Table 1 Calculation For M8 And M10

\begin{tabular}{|l|l|}
\hline for M8 & for M10 \\
$\sigma 1, \sigma 2=(4.973 / 2)+-\sqrt{ }((4.973 / 2) 2+$ & $\sigma 1, \sigma 2=(3.183 / 2)+-\sqrt{ }((3.183 / 2) 2+$ \\
$(4.973) 2)$ & $(3.183) 2)$ \\
$\sigma 1=8.046 \mathrm{~N} / \mathrm{mm}^{2}$ & $\sigma 1=5.148 \mathrm{~N} / \mathrm{mm}^{2}$ \\
$\sigma 2=-3.074 \mathrm{~N} / \mathrm{mm}^{2}$ & $\sigma 2=-1.968 \mathrm{~N} / \mathrm{mm}^{2}$ \\
$\tau \max (\mathrm{M} 8)=(8.046-(-3.074)) / 2$ & $\tau \max (\mathrm{M} 10)=(5.148-(-1.968)) / 2$ \\
$\tau \max =5.56 \mathrm{~N} / \mathrm{mm}^{2}$ & $\tau \max =3.558 \mathrm{~N} / \mathrm{mm}^{2}$ \\
\hline
\end{tabular}

\section{Finite Element Analysis}

The threaded fasteners plate M8 and M10 bolt is the one of the most important fasteners used in the industry. A detailed analysis and significant research efforts have been devoted to the investigation of the bolt joint M8 \& M10 circular bolt. The effect of variable parameters such as stress, strain and displacement are computed in the structural analysis under the static load condition.
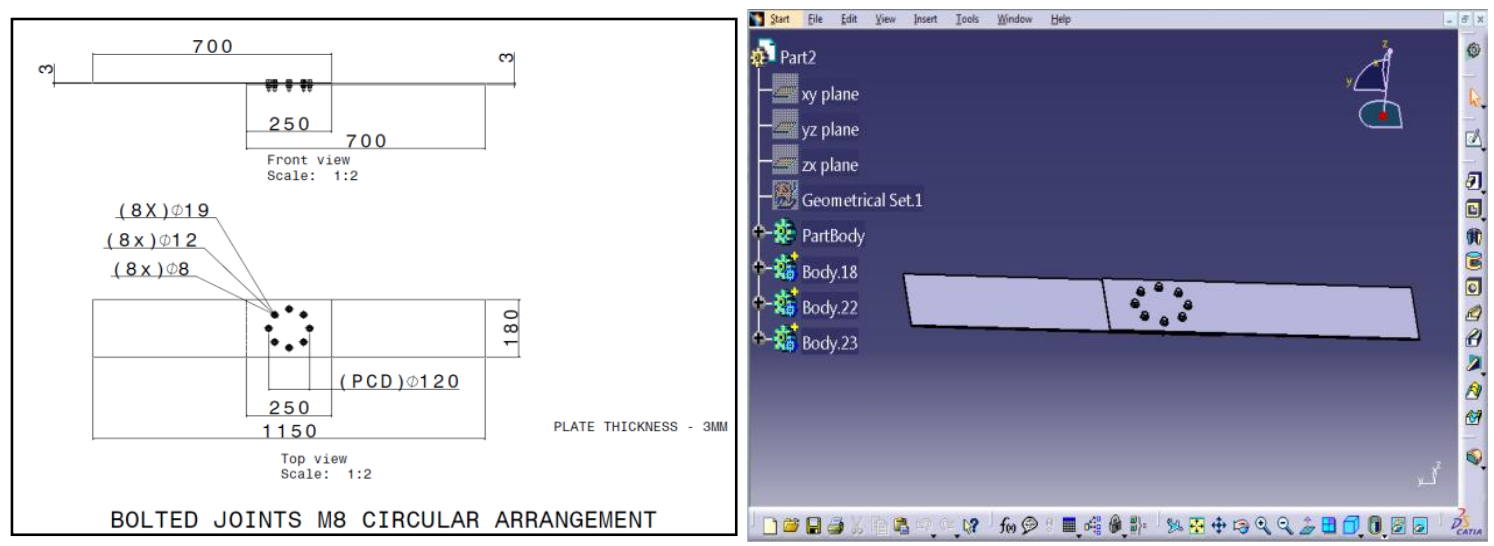

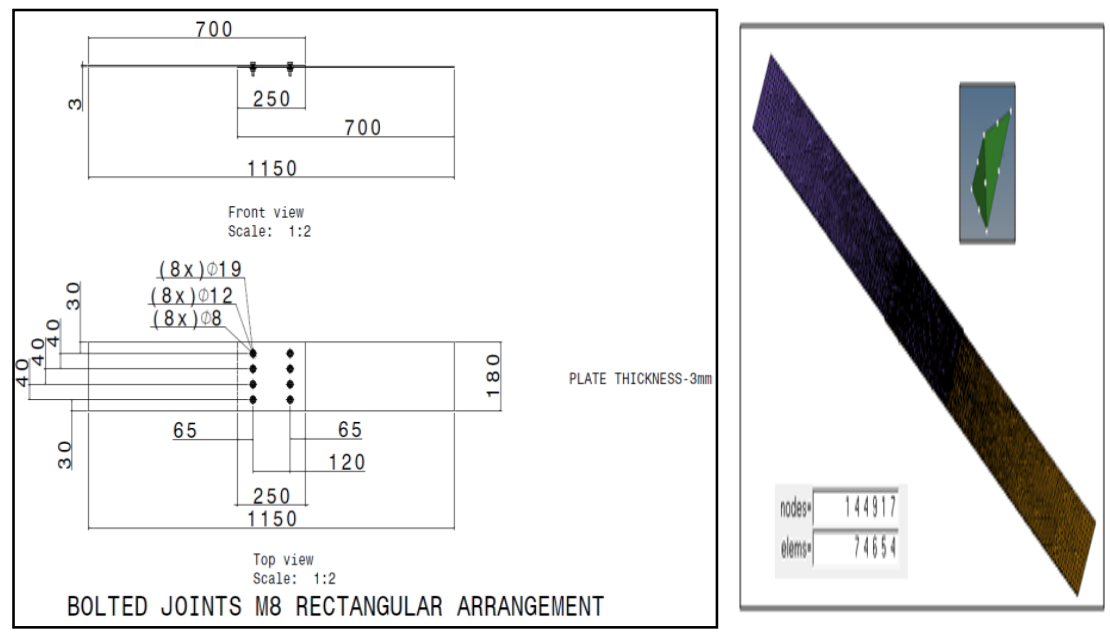

\section{Mesh Yodel - \\ Nootedements $=760.4$}

Soofilodes $=[49917$

Pre Processing =Hyperlesen 11

Solver =RADIOSS

Post Processing =Hyperverew

Analysis $=$ Nond'meay quasi-Static

Materal $=$ Stee cass Propintary material
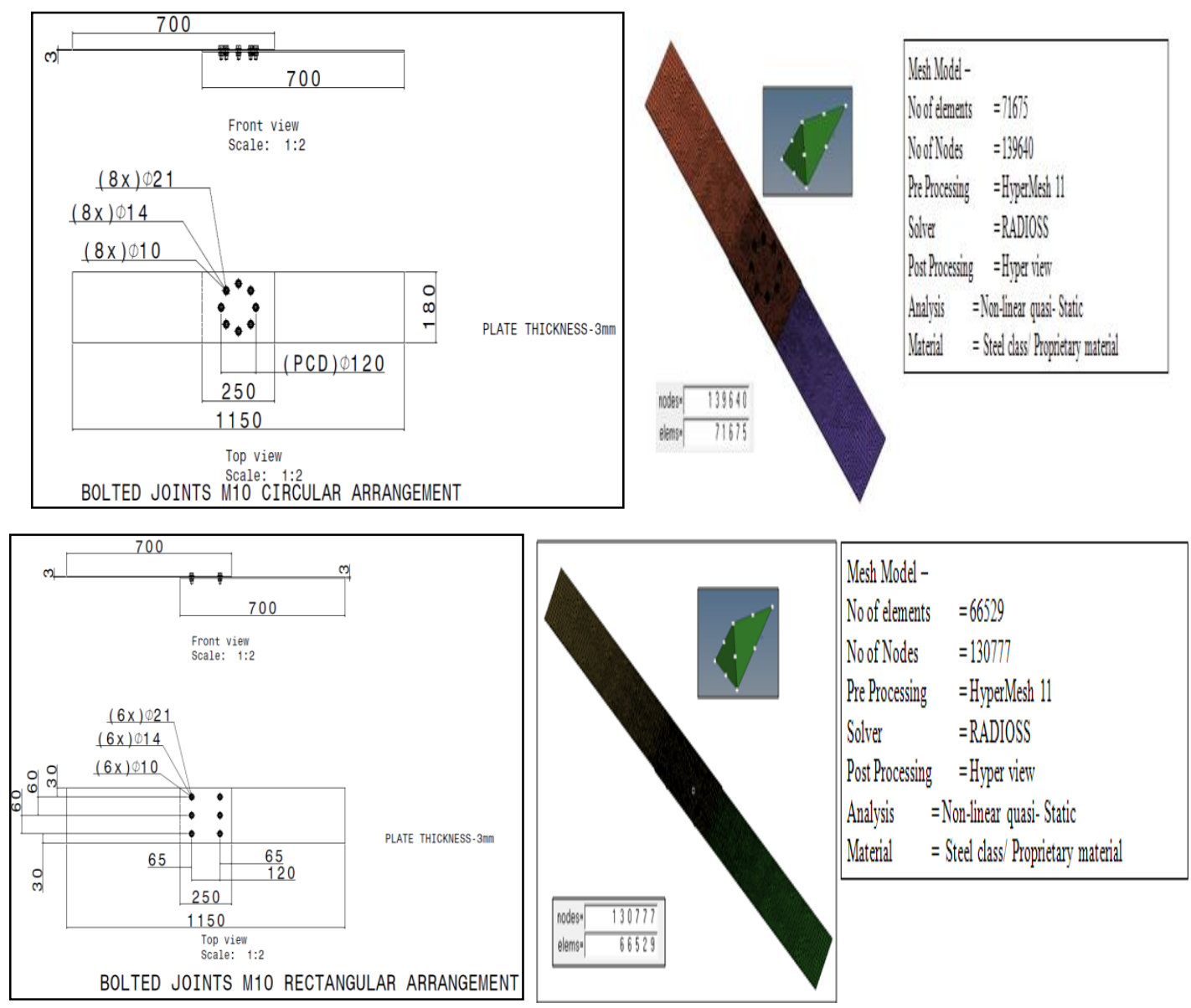

Figure 4.1 2D Geometry for bolted joints M8 \& M10 circular arrangement \& 3D Geometry for bolted joints M8 \& M10 circular arrangement.

\section{Defining Material Properties}

The CAD model of M8 bolt circular converted in to STEP file. This model is imported in to HYPERMESH workbench. The properties of carbon steel class are defined to software. The material properties of steel are as. $\left(E=2.1 \times 10^{\wedge} 5 \mathrm{~N} / \mathrm{mm}^{2}\right.$, Poisson Ratio=0.3, Density $=7.89 \times 10^{\wedge}-9$ ton $\left./ \mathrm{mm}^{3}\right)$

\begin{tabular}{|c|c|c|c|c|}
\hline \multirow{2}{*}{$\mathrm{MAT} 1$} & ID & {$[E]$} & \multirow{2}{*}[\mathrm{G}]{} & $\begin{array}{ll}\mathrm{NU}] & {[\mathrm{RHO}]}\end{array}$ \\
\hline & & $\longdiv { 2 . 1 e + 0 5 }$ & & $0 . 3 0 0 \longdiv { 7 . 9 e - 0 9 }$ \\
\hline & [ST] & {$[\mathrm{SC}]$} & [SS] & \\
\hline
\end{tabular}

Figure 4.2 Defining Material Properties 


\subsection{Mesh Generation (Pre-Processing) \\ 4.6.1 Geometry Cleanup}

It is to mesh thereby forming good input for FEM,initially solid component developed then convert it into surface modeling with tolerance 0.01 global clean up tolerance, The model is then checked for non-manifold edges where there are two surfaces sharing an edge, which might indicate incorrect connectivity. Duplicate surfaces are also checked with clean-up tolerance 0.01 and then deleted.

\subsubsection{Pre-Processing (Meshing)}

Ones the geometry is cleaned up, all the surfaces are meshed with 2D trial element to form a closed mesh. 3D tetrahedral element created from the closed 2D mesh so as to form threaded fasteners plate component. The second order tetrahedral meshing approach is employed for the meshing of the fasteners plate geometry as shown in Figure 4.4
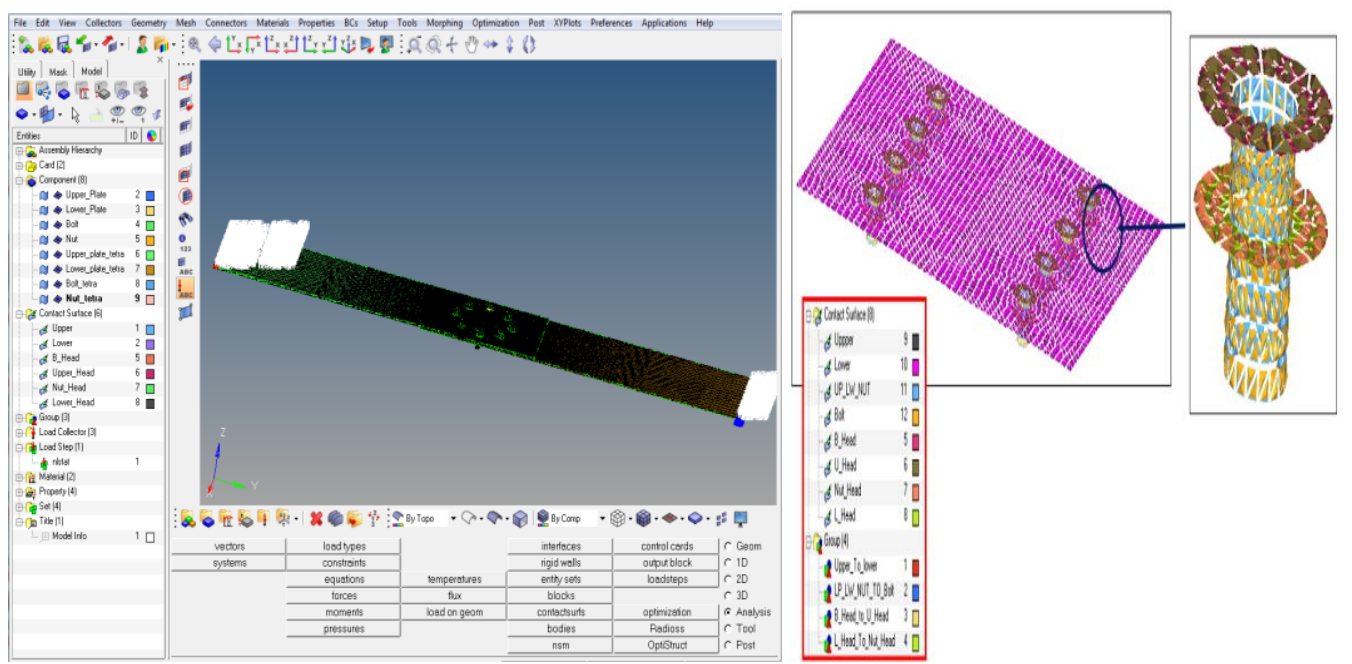

Figure.4.3 Meshing M8 circular bolted joints arrangement plate \& Interface M8 circular bolted joints arrangement plate

Tetrahedral meshing produces high quality meshing for boundary representation of solid structural model. Since the tetrahedral is found to be the best meshing technique. Divide the whole model into several parts and mesh one by one in different mesh densities. Although meshing by this way can produce more elements than by painstaking meshing, the advantages of saving time and easy operation is excellent. In addition, you can trim the surface artificially and a new surface edge will produce which will be the element edge after meshing

1- Element size should be taken in such a way so that every geometry feature should be captured in mesh. 2 mm element size should be taken.

2- More the number of elements accuracy will increase but solution time will also increase so a proper combination between accuracy and solution time should be considered while choosing the element size.

3- When meshing is done, elements should satisfy certain element criteria for best results which is shown below,

\section{Processing (or) Solution (applying boundary conditions)}

To observe maximum stress produce into the M8 circular bolted joint plate, model is subjected to extreme condition (abuse load) and stress structural analysis is carried out using HYPERWORKS and RADIOSS solver. After pre-processing, Loads \&boundary conditions are applied as shown in Figure 4.4

1- Boundary conditions is $2000 \mathrm{~N}$ force is applied at top of M8 circular bolted joint plate.

2- Constraint (1-6) at lower side. 

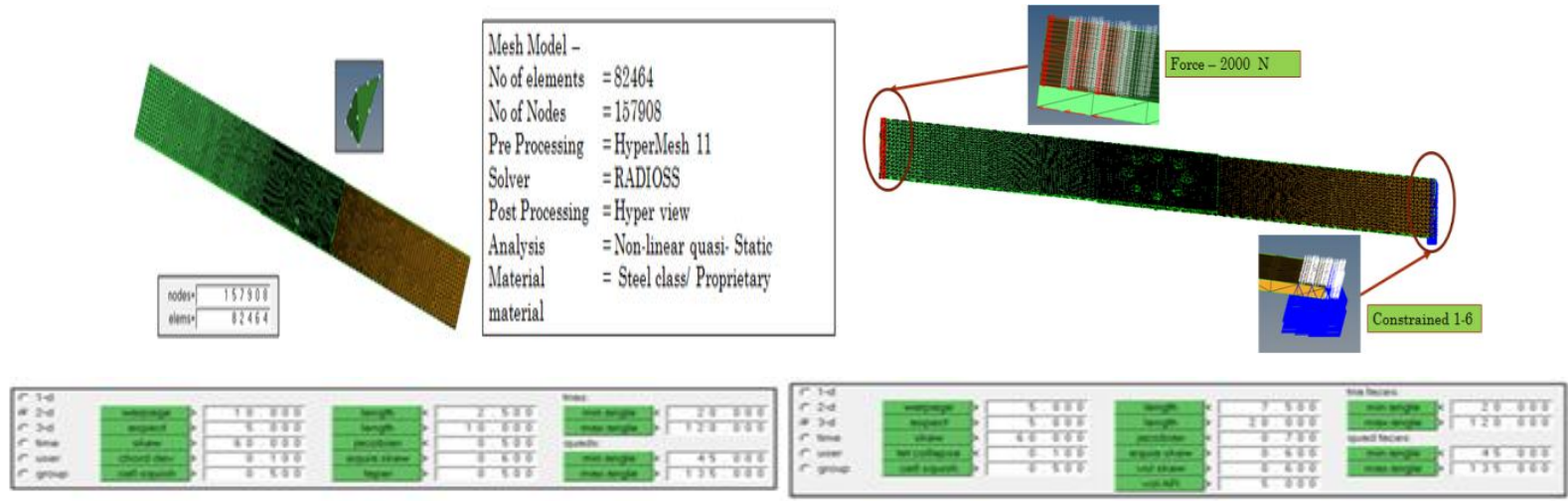

Figure 4.4 Finite Element Entites \& Figure 4.7Boundary conditions of M8 circular bolted joint plate 4.6.4 Post Processor

In this phase of solution the M8 circular bolted joint plate Model is used for finding out the values of stress during the various loading condition. Following parameters are predicted during post processing phase.

i. $\quad$ Stress

ii. Displacement

iii. Maximum shear stress

Firstly the component was designed for that elemental stress and displacement results are obtained from hyper works.
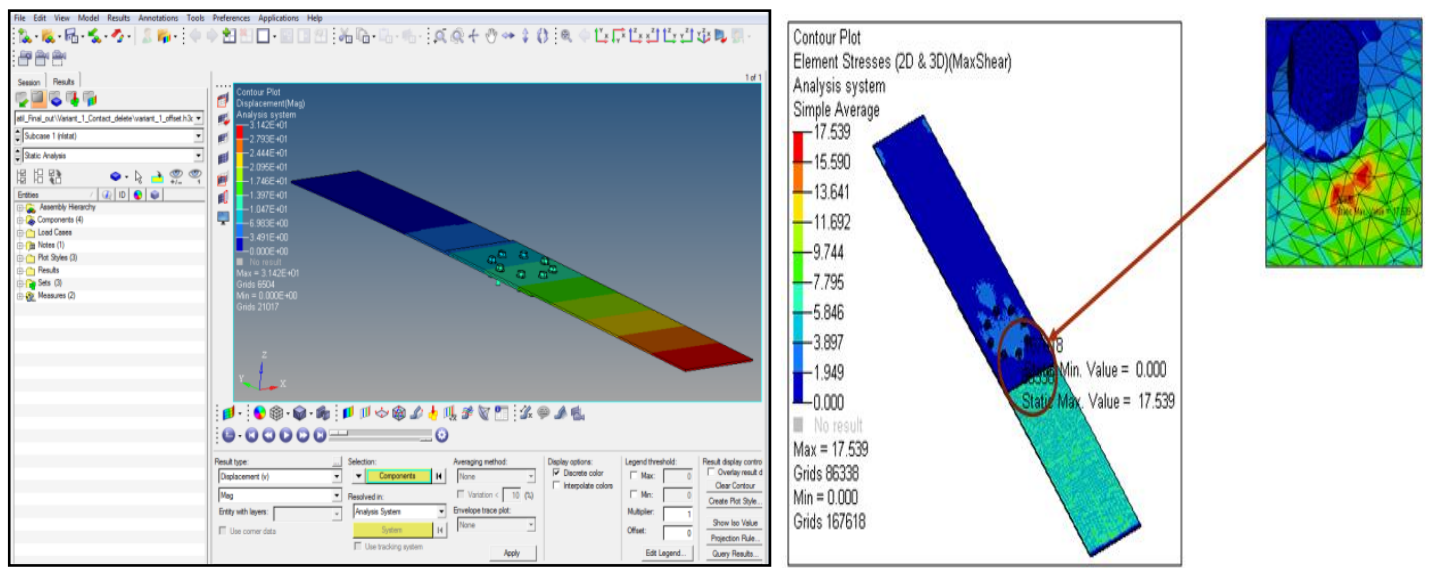

Figure 4.5 Hypermesh view and Stress counter M8 circular bolted joint plate
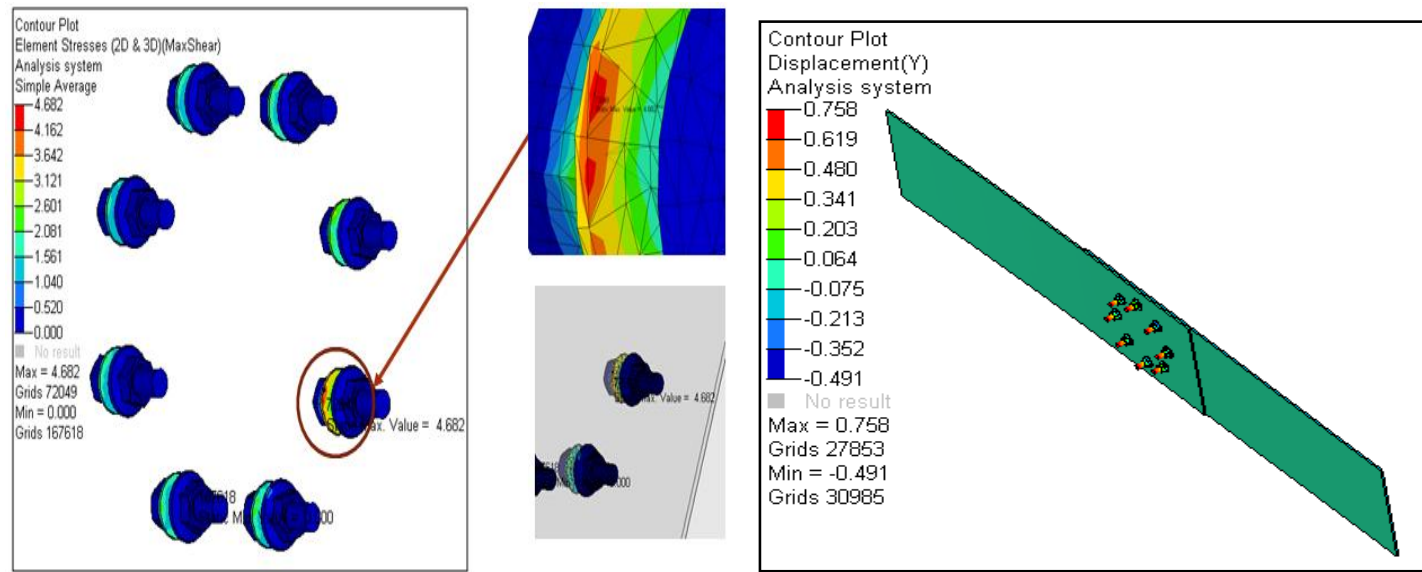

Figure 4.6 Maximum Stress in Bolt and Displacement counter in Bolt 


\section{Summary}

i. $\quad$ The M8 circular bolted joint analyzed under load of $2000 \mathrm{~N}$ is applied.

ii. The Maximum shear stress observed 17.54Mpa.

iii. The Max Displacement Observed $0.758 \mathrm{~mm}$

iv. The Maximum shear stress in bolt observed 4.68Mpa.

\subsubsection{Optimization approach}

Optimization is defined as the automatic process to make a system or component as good as possible based on an objective function and subject to certain design constraints. Optimization is the technique in which the better solution has been finds out in order to have the better design by weight, cost and strength and rigidity criteria. By applying various boundary conditions and load on the fasteners plate. From the Figure we observed that for the existing fasteners plate assembly showing the elemental stress distribution. By observing the stress distribution we finding the low stress area where we can modify the geometry the low stress area where we can remove material that not bears the load. For removal of material we have to consider the manufacturing aspect and some functional constraint. The feasibility of tooling required for modified geometry should check at the time of material removal. Blue and gray

Colour region describes dead zone or low stress region, elements from same region are not contribute to external load.

\subsubsection{M8 rectangular bolted joint plate (Variant no-2)}

The incremental approach for iterations is carried out on benchmark which is given as follows.
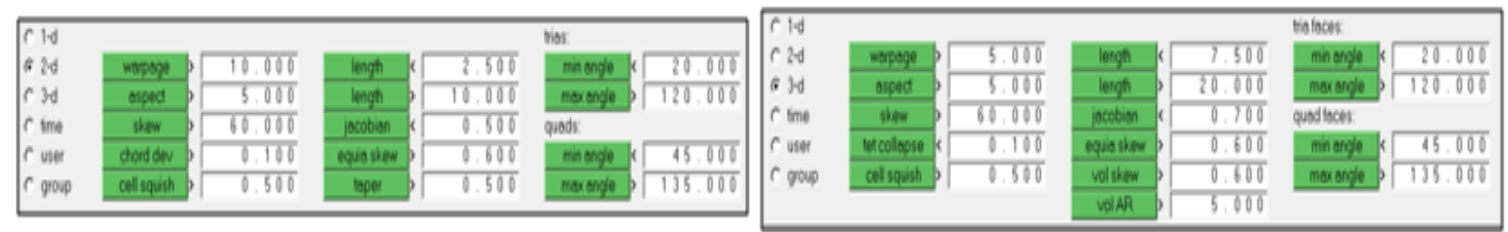

Figure 4.7 2D Geometry for bolted joints M8 rectangular arrangement (Benchmark or Variant 2) Figure 4.13 Finite Element Entites-M8 rectangular bolts

a) Total length of the plate is $1150 \mathrm{~mm}$.

b) M8 rectangular bolt diameter is $19 \mathrm{~mm}, 12 \mathrm{~mm}$ and $8 \mathrm{~mm}$.

In the variant no 1in which M8 bolted joint plate circular pattern is used. And variant no 2 in M8 bolted joint plate rectangular pattern is used. The component was designed for that elemental stress, displacement and maximum shear stress results.
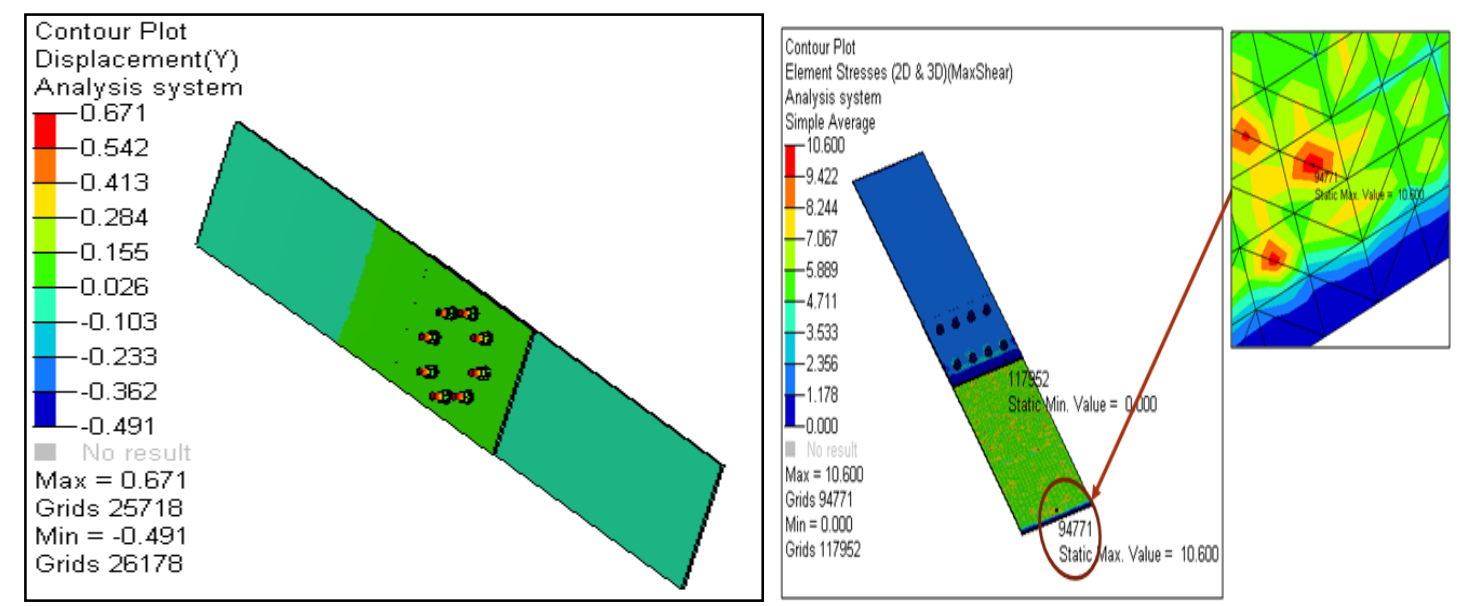

Figure 4.8 Displacement counter M8 rectangular bolt plate and Stress counter M8 rectangular bolt plate 

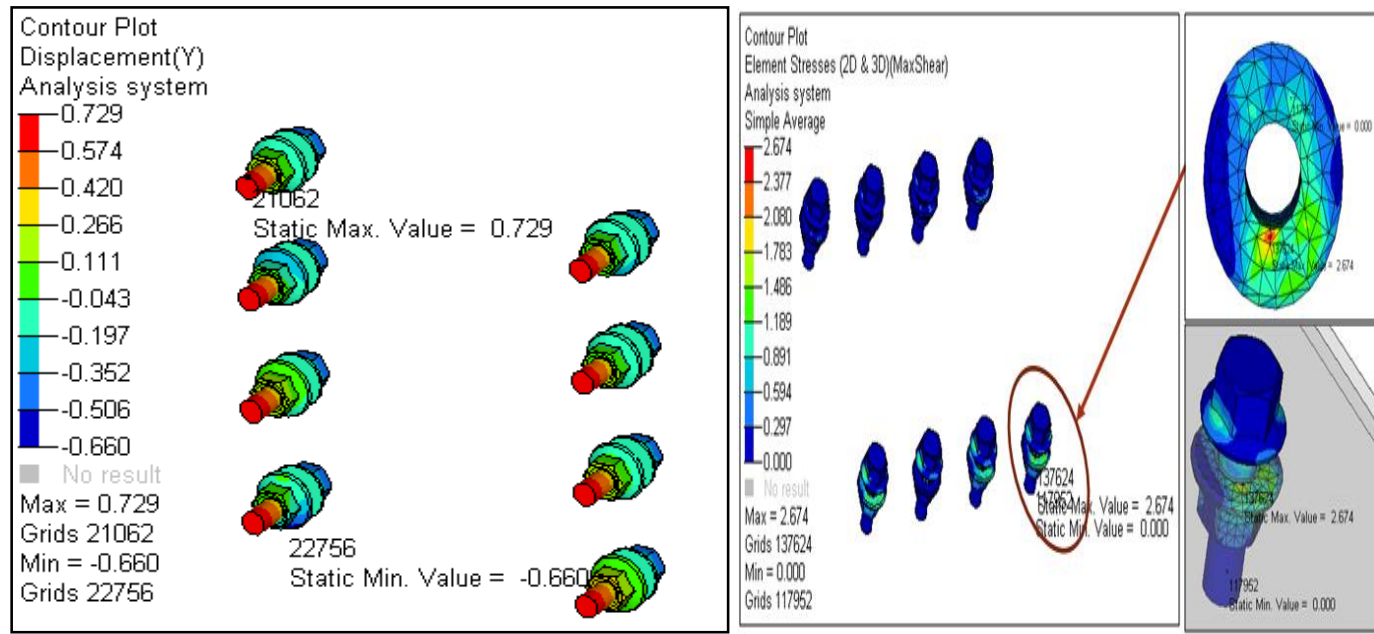

Figure 4.9 Displacement counter M8 rectangular bolt

Figure 4.10 Maximum Shear Stress in M8 rectangular bolt

\section{Summary}

i. $\quad$ The M8 rectangular bolted joint analyzed under load of $2000 \mathrm{~N}$ is applied.

ii. The Maximum shear stress observed 10.60Mpa.

iii. The Max Displacement Observed $0.729 \mathrm{~mm}$

iv. The Maximum shear stress in bolt observed 2.67Mpa.

\subsubsection{M10 circular bolted joint plate (Variant no-3)}

The incremental approach for iterations is carried out on benchmark which is given as follows.
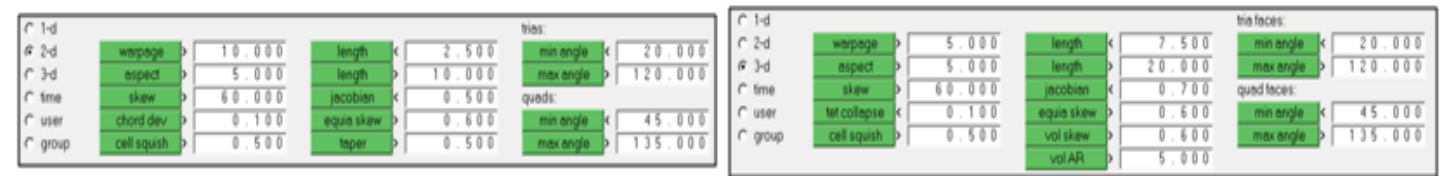

Figure 4.10 2D Geometry for bolted joints M10 circular arrangement (Variant 3) Figure 4.19 Finite Element Entites-M10 circular bolt

a) Total length of the plate is $1150 \mathrm{~mm}$.

b) M8 rectangular bolt diameter is $21 \mathrm{~mm}, 14 \mathrm{~mm}$ and $10 \mathrm{~mm}$.

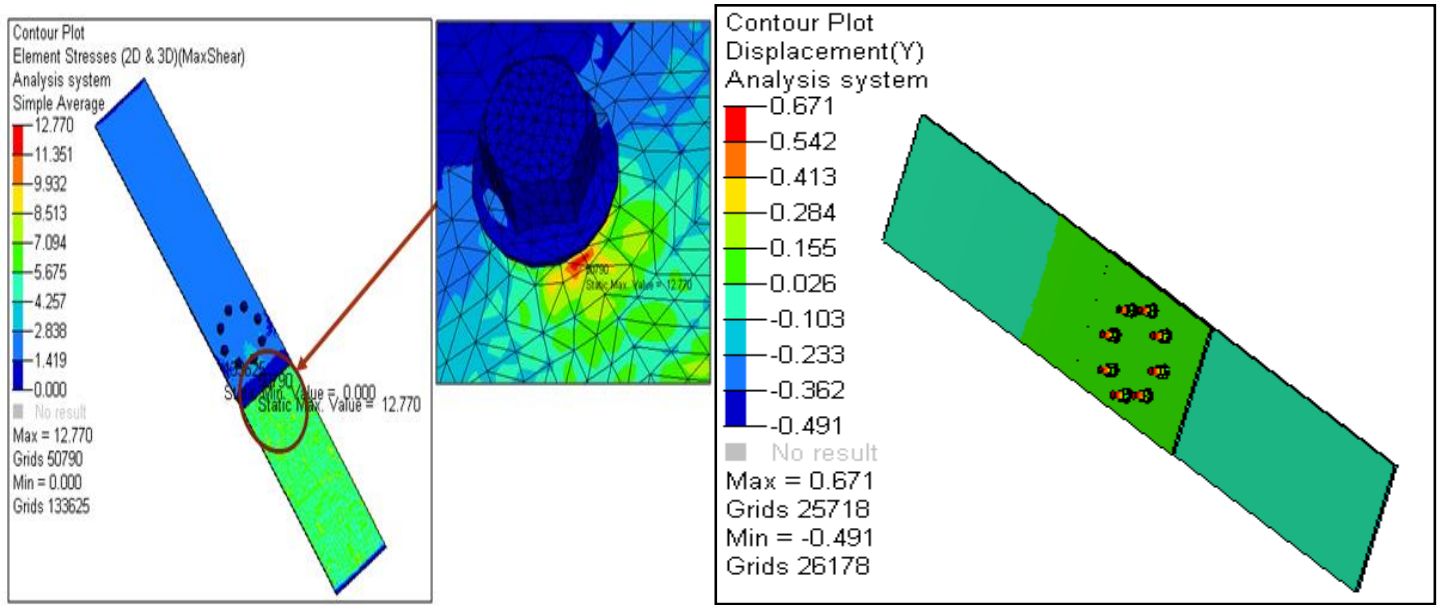

Figure 4.11 Stress counter M10 circular bolted joint plate Figure \& Displacement counter M10 circular bolt plate 


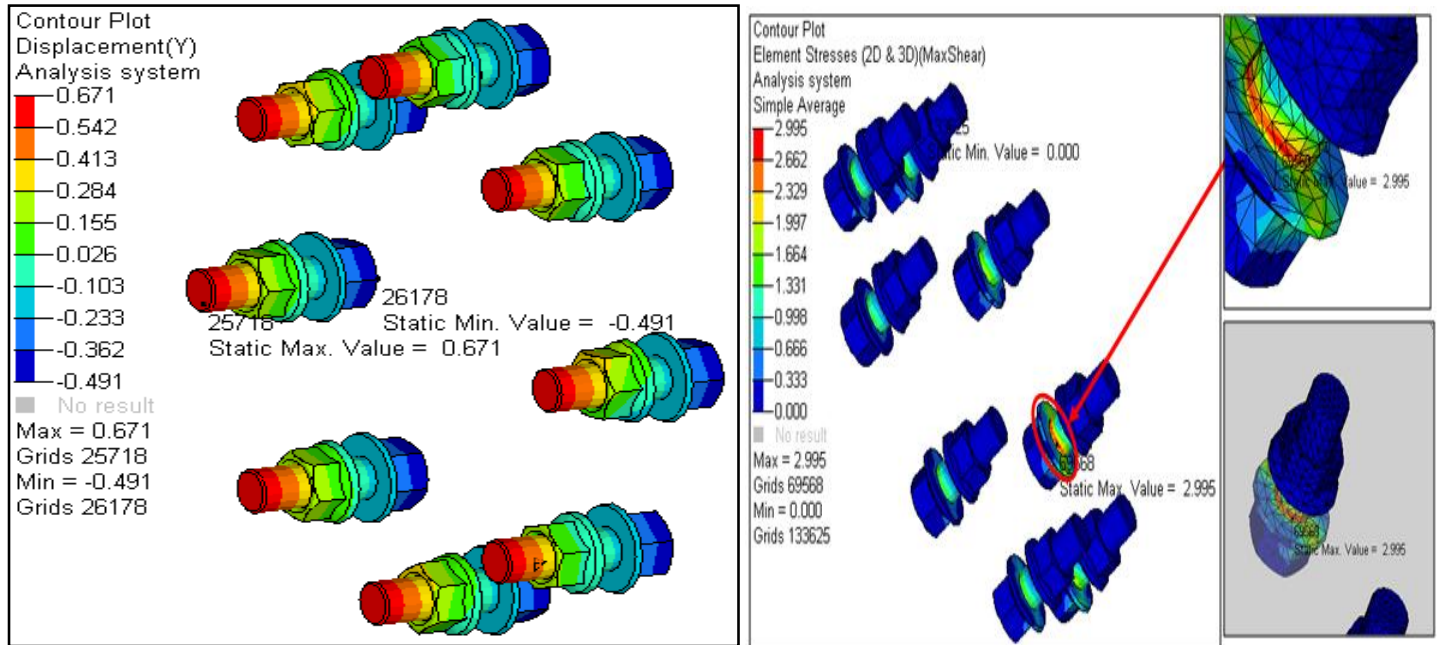

Figure 4.12 Displacement counter M10 circular bolt Figure 4.23 Maximum Shear Stress in M10 circular bolts

\section{Summary}

1- The M8 rectangular bolted joint analyzed under load of $2000 \mathrm{~N}$ is applied.

2- The Maximum shear stress observed 12.77Mpa.

3- The Max Displacement Observed $0.671 \mathrm{~mm}$

4- The Maximum shear stress in bolt observed 2.99Mpa.

\subsubsection{M10 rectangular bolted joint plate (Variant no-4)}

The incremental approach for iterations is carried out on benchmark which is given as follows.
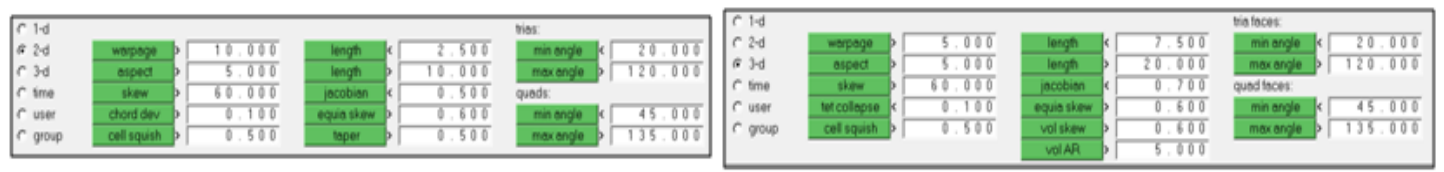

Figure 4.13 2D Geometry for bolted joints M10 rectangular arrangement (Benchmark or Variant 4)

a) Total length of the plate is $1150 \mathrm{~mm}$.

b) M8 rectangular bolt diameter is $21 \mathrm{~mm}, 14 \mathrm{~mm}$ and $10 \mathrm{~mm}$.
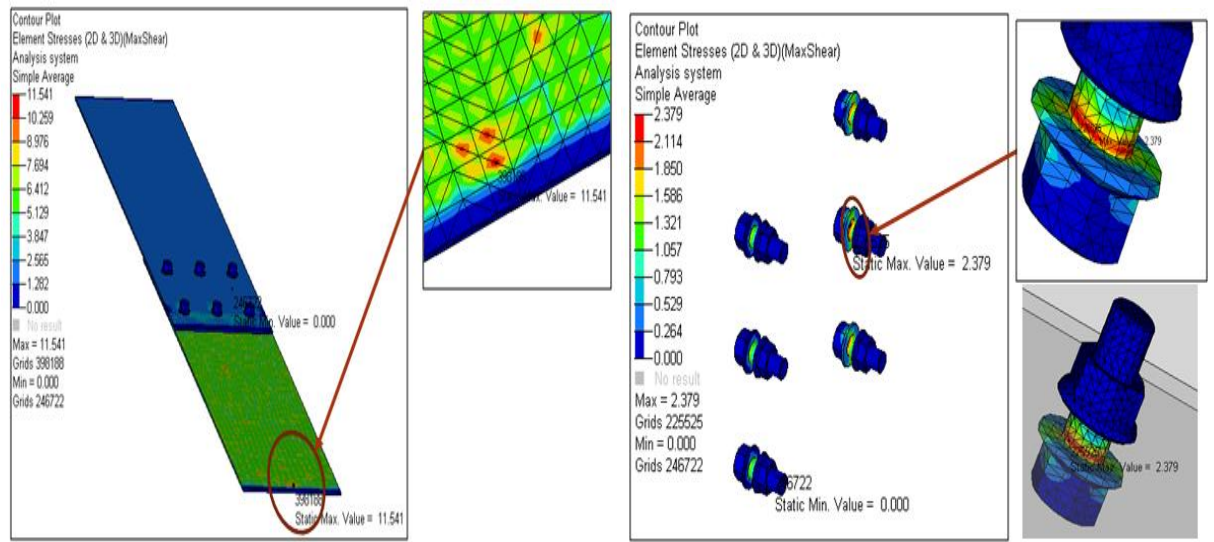

Figure 4.14 Stress counter M10 rectangular bolted joint plate and Maximum Shear Stress in M10 rectangular bolte 


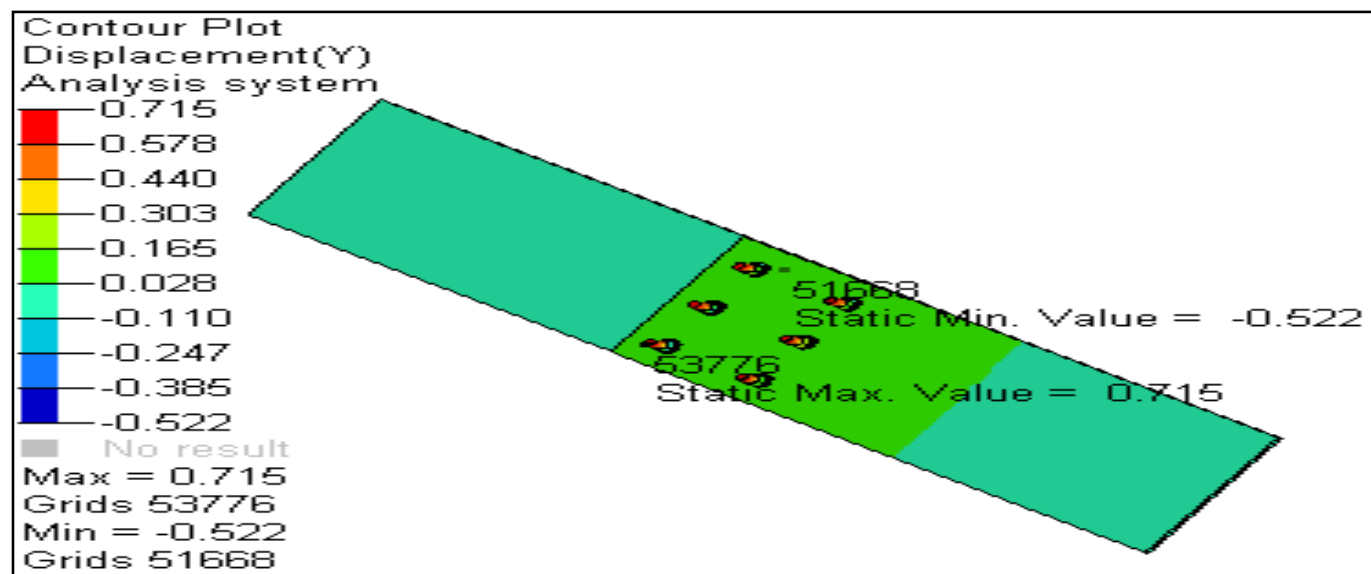

\section{Summary}

Figure 4.16 Displacement counter M10 rectangular bolt plate

1- The M8 rectangular bolted joint analyzed under load of $2000 \mathrm{~N}$ is applied.

2- The Maximum shear stress observed 11.54Mpa.

3- The Max Displacement Observed $0.715 \mathrm{~mm}$

4- The Maximum shear stress in bolt observed 2.38Mpa.

\subsubsection{Comparison Displacement counters variant 1 to 4}

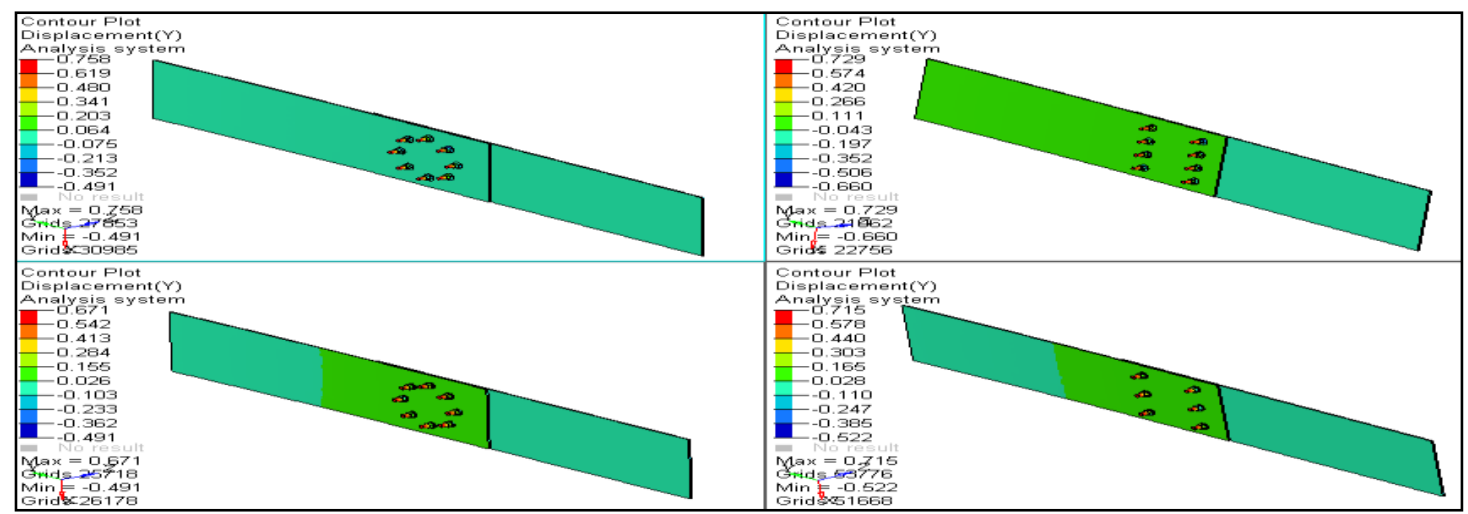

Figure 4.17 Displacement counters variant 1 to 4

\subsubsection{Comparison Stress counters variant 1 to 4}

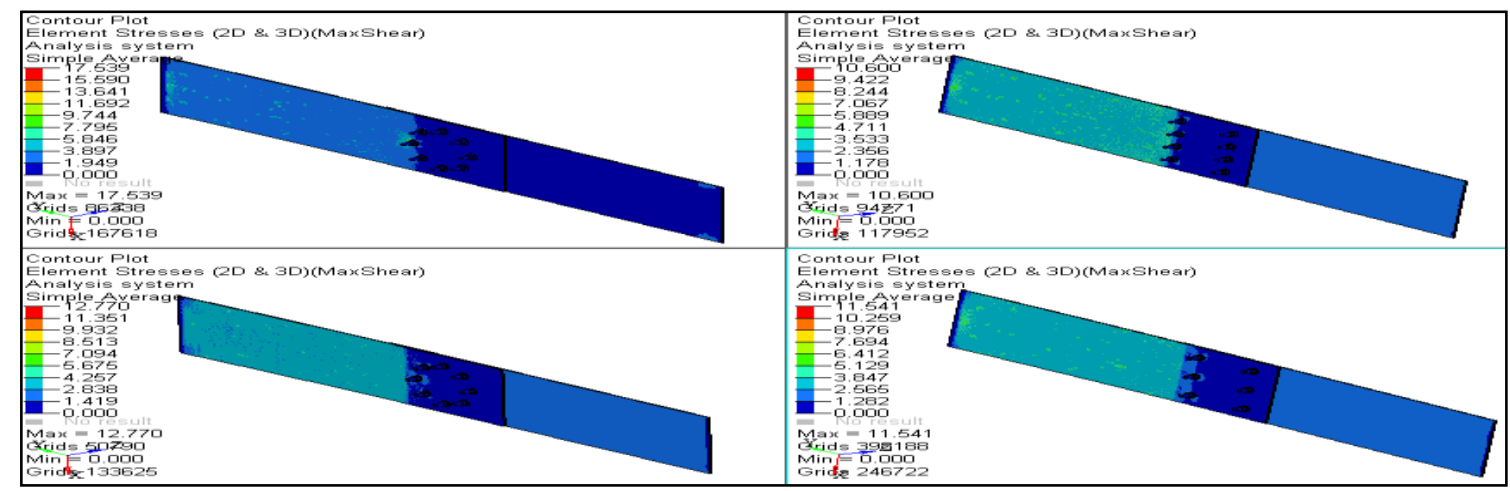

Figure 4.18 Stress counters variant 1 to 4 in modal 
4.6.11 Comparison Stress counters of bolt variant 1 to 4

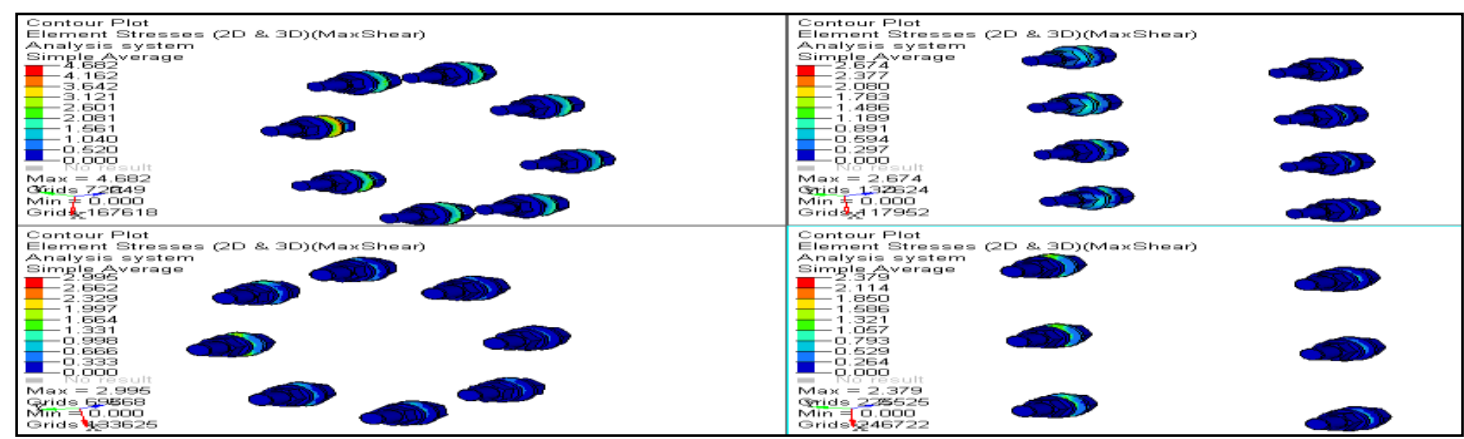

Figure 4.18 Stress counters of bolt variant 1 to 4

5. Result \& conclusion

5.1 HYPERMESH Result for circular and rectangular arrangement nut bolt M8 and M10 size

\begin{tabular}{|c|c|c|c|}
\hline Variant No & $\begin{array}{c}\text { Displacement } \\
\text { (mm) }\end{array}$ & $\begin{array}{c}\text { Max Sheax } \\
\text { Stress (MPa) }\end{array}$ & $\begin{array}{c}\text { Max Sheax } \\
\text { Stress in Bolt } \\
\text { (MPa) }\end{array}$ \\
\hline 1.CIRCULER-M8) & 0.758 & 17.54 & 4.68 \\
\hline 2(RECTAGULER-MS) & 0.729 & 10.60 & 2.67 \\
\hline 3 (CIRCULER-MI10) & 0.671 & 12.77 & 2.99 \\
\hline 4 (RECTAGULER-M10) & 0.715 & 11.54 & 2.38 \\
\hline
\end{tabular}

Table 5.1 Hypermesh result

According to Hypermesh result we seen that for safe result the maximum shear stresses for M8 nut bolt for mathematical calculations are are $5.55 \mathrm{Mpa}$ and this arrangement gives $4.68,2.67 \mathrm{Mpa}$ so M8 arrangement arrangement is reduces vibration or displacement \&M10 has 3.55 mpa safe max shear stress so 2.99,2.38 Mpa are safe.

5.2Comparasion chart for all variant

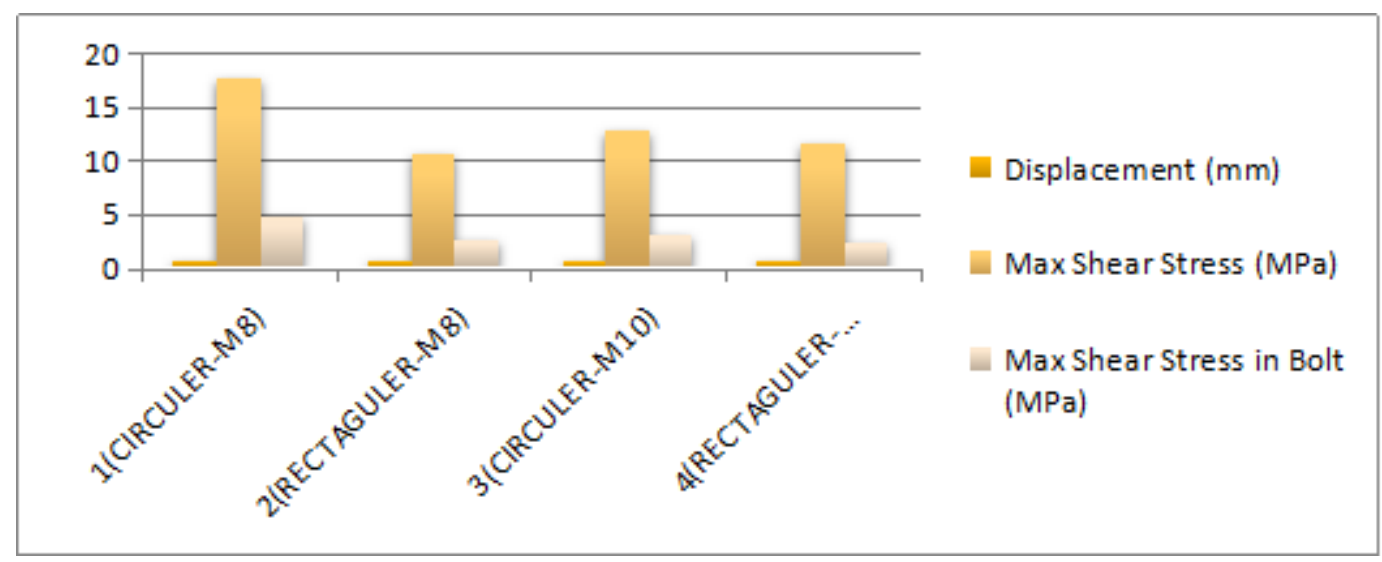

Graph 5.1 Comparasion chart for all variant

Table 5.1. Hypermesh result for circular and rectangular arrangement nut bolt M8 and M10 size

i. $\quad$ Stress in fasteners for the Variant 1, Variant 2, Variant 3 and Variant 4 were found to be 4.68, 2.67, 2.99 , and $2.38(\mathrm{MPa})$ respectively. 
ii. It is observed that, the value of Stress is lower for the square arrangement 2.38, 2.67 MPa. Higher size of bolt (M10 compared with M8) has registered a lower amount of stress.

iii. The variant with square arrangement (Variant No.2 \& 4), showed uniform stress distribution as compare to circular arrangement.

iv. The stress level observed for Variant 4 with 6 number of bolt is about $2.38 \mathrm{MPa}$. This is the recommended variant among the alternatives.

5.3 Percentage reduction comparison rectangular array M8 and circular array M10 bolt

\begin{tabular}{|l|l|l|l|}
\hline Nut bolt Type & $\begin{array}{l}\text { Displacement in } \\
\mathrm{mm}\end{array}$ & $\begin{array}{l}\text { Maximum shear } \\
\text { stress in (Map) }\end{array}$ & $\begin{array}{l}\text { Maximum shear } \\
\text { stress in (Map) in } \\
\text { bolt }\end{array}$ \\
\hline Rectangular-M8 & 0.729 & 10.6 & 2.67 \\
\hline Circular-M8 & 0.758 & 17.54 & 4.68 \\
\hline $\begin{array}{l}\text { \% Reduction in } \\
\text { M8 }\end{array}$ & 96.17 & 60.4 & 57.05 \\
\hline
\end{tabular}

Table 5.2 comparison rectangular array M8 and circular array M10 bolt

The above table shows that

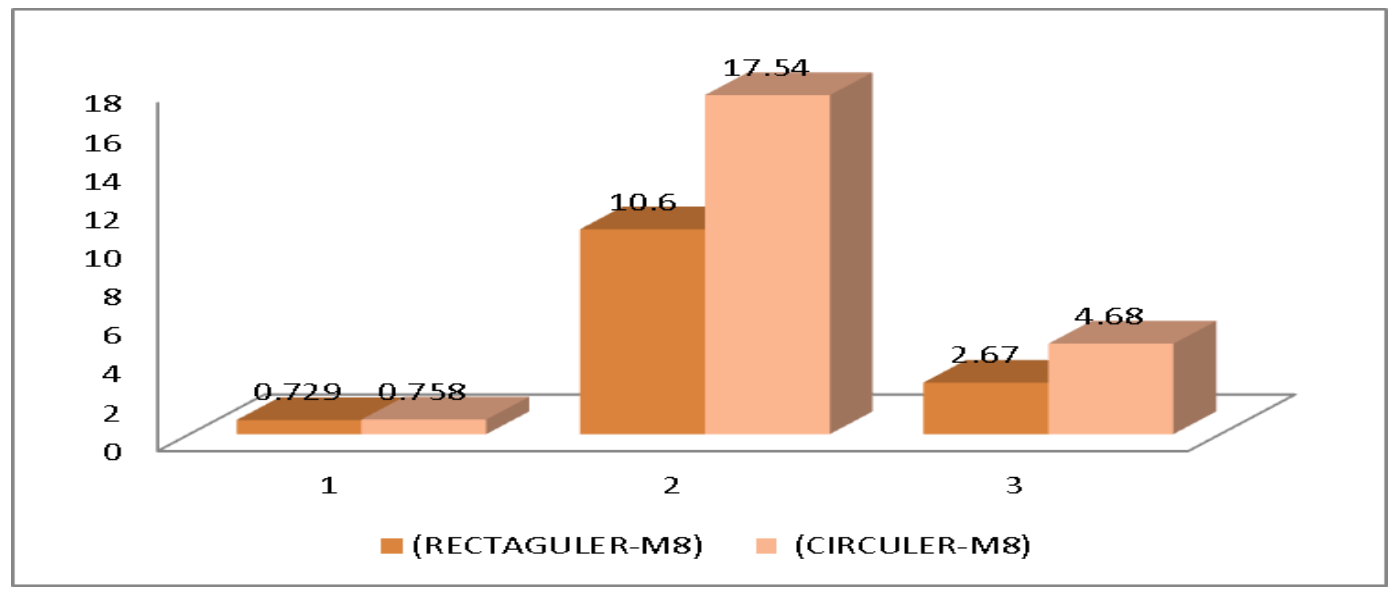

Graph 5.2 Comparison Graph rectangular array M8 and circular array M8 bolt

\section{REFERENCES}

1- Alexander Salenikovich, "Analytical model for predicting brittle failures of bolted timber joints", Materials and Structures, (2009) 42:67-875.

2- Chen Kun-Kun, Wang Hai, "Analysis of Through-the-Thickness Stress Distribution in Thick Laminate Multi-Bolt Joints Using Global-Local Method”, J. Shanghai Jiaotong Univ. (Sci.), Vol 18(3), 2013, 326-333.

3- D.Valladares, M. Carrera, L. Castejon, "Development of a Numerical Technique for the Static Analysis of Bolted Joints by the FEMS", Proceedings of the World Congress on Engineering 2013 Vol III, ISBN: 978-988-19252-99.

4- Hsiu-Ying Hwang, "Bolted joint torque setting using numerical simulation and experiments", Journal of Mechanical Science and Technology 27 (5) (2013) 1361 1371.

5- Iuliana Piscan, Nicolae Predincea, "Finite Element Analysis of bolt joint", Proceedings in Manufacturing Systems, ISSN 2067-9238 Vol. 5,2010,167-172. 